\title{
Learning Disabilities as a Non-negative Ontology: Mental Hygiene, Medicalization and Education
}

\author{
SAI TZY HORNG \\ Simon Fraser University
}

\begin{abstract}
The field of learning disabilities $(\mathrm{LD})$ is divided between mainstream and contextualist perspectives of $L D$. Both perspectives view $L D$ as a negative ontology (Baker, 2002). A negative ontology refers to disabilities as inherently problematic; individuals labelled as disabled will inevitably have poorer outcomes (Campbell, 2000). This paper argues that a unified view of $L D$ begins with viewing $L D$ as a non-negative ontology. To understand $L D$ as a non-negative ontology requires first a critical consciousness of the historical formations of $L D$ as a negative ontology. In particular, this paper provides an overview of various historical arguments on how medicalization and the mental hygiene movement framed $L D$ as a negative ontology.
\end{abstract}

\section{Introduction}

The field of learning disabilities (LD) is divided between mainstream perspectives of LD and contextualist perspectives. Neufeld and Hoskyn (2004) have suggested that a more unified field of LD will provide better services for students and a more comprehensive understanding of LD. Mainstream perspectives of $\mathrm{LD}$ focus on scientific investigations of $\mathrm{LD}$ as cognitive/neurological problems located within individuals (Hynd, Clinton, \& Hiemenz, 1999; Hallahan \& Devery, 2003; Kavale \& Forness, 2003). Mainstream approaches also place little emphasis on the importance of contextual factors of LD. Contextual factors refer to a host of social, economic, political and historical factors. As a result, mainstream approaches to LD pay little attention to the social practices that contribute to the characterization of LD as a within-individual problem. Proponents of contextualist perspectives of LD such as Carrier (1983), Christensen (1993), Danforth \& Rhodes (1997), Reid and Valle (2004), and Skrtic (1999), on the other hand, argue that LD is a socially-created concept and have criticized mainstream perspectives of LD for being overly focused on framing LD as a problem that is located within individuals. Similarly, contextualist perspectives emphasize that mainstream modes of inquiry into LD depict an incomplete and incorrect understanding of LD and also suggest that mainstream explanations of LD often result in a loss of individual agency within individuals with LD (Oliver, 2000; Danforth \& Gabel, 2006). In addition, contextual perspectives of LD are concerned with existing social practices that oppress individuals with LD (Carrier, 1983; Christensen, 1997; Danforth \& Gabel, 2006).

Although both mainstream and contextual perspectives differ in their explanations of LD, they both characterize LD as a problem; each perspective characterizes LD as a problem in its own way. Baker (2002) and Campbell (2000; 2005) argue that disability is a negative ontology. The term negative

(C) Copyright 2006. The author, Sai Tay Horng, assigns to the SFU Educational Review the right of first publication and educational and non-profit institutions a non-exclusive license to use this document for personal use and in courses of instruction provided that the article is used in full and this copyright statement is reproduced. Any other usage is probibited without the express permission of the author. 
ontology refers to disability as a "headache that won't go away" (Campbell, p.306) because it is a human condition that "must not be desired" (Baker, p.685). In other words, disabilities, including LD, are a highly problematic and undesirable human condition. For Baker and Campbell, it is the ways in which scholarly and institutional inquiries into, and the public view of LD that has framed LD as a negative ontology. Framing LD as a negative ontology, according to Baker and Campbell, suggests that individuals with $\mathrm{LD}$ will almost always remain a permanent problem.

According to Baker (2002), both mainstream and contextualist perspectives frame LD as a negative ontology. In addition, Neufeld and Takacs (2006) suggest that within the field of LD, there is an overemphasis on determining the etiology of LD within the individual. While mainstream perspectives attempt to determine the etiology of LD within the neurobiological composition and cognitive function of individuals, contextual perspectives find etiological factors within social practices and one's sociocultural situation. According to Baker, finding etiological factors of disabilities suggests finding causes to a problem; the act of finding causes to a problem frames individuals with disabilities as a problem. Thus Baker indicates that both perspectives motivate an ableist normativity and reinforce ableist norms; researchers of both perspectives continuously search for individuals with disabilities to maintain ableist norms. An ableist normativity refers to the ongoing institutional practices, discourses, technologies and everyday activities that maintain ideal ways of "being seen as fully human" (Campbell, 2000, p.112). According to Baker, the existence of ableist norms in society reinforces LD as a negative ontology by making disabilities a distinct social category that will never fit within ableist norms.

The division in the field of LD is worsened with little discussion regarding how both perspectives can complement each other to better provide for individuals with LD. The emphases on etiology by mainstream and contextualist perspectives create a divide between both perspectives as they pursue different etiological explanations of LD. Thus, I argue that a unified view of LD may begin with understanding LD as a non-negative ontology. Understanding LD as a non-negative ontology requires both mainstream and contextualist perspectives to reduce searching only for etiological factors and problematizing LD. A focus on positive qualities of individuals with $\mathrm{LD}$ may help reframe it as a non-negative ontology. Furthermore, there may be more benefits to society if proponents of both perspectives collaborate to empower individuals with LD.

Before LD can be understood as a non-negative ontology, a broader understanding of social and historical processes that have led to current social practices and current ideologies that maintain and/or reinforce the status quo of $\mathrm{LD}$ is required. A reframing of LD from a negative ontology to a nonnegative ontology requires a critical consciousness from all sectors of society, particularly educators, parents and individuals labelled with LDs (Brantlinger, 2004; Graham \& Grieshaber, 2006). King (1991) uses the term "dysconsciousness" (p.135) to describe a mindset where one takes for granted the current social practices as a naturalized matter of fact; society becomes ignorant of the historical significance of oppressive social practices. Educators, according to Baker (2002), often forget the historical formations of the practices they exercise in schools and are unaware that they are reinforcing ableist norms. These historical processes include understanding key historical events behind the formation of the existing social framework in which schools are situated, as well as understanding the historical formation of medical and classifying practices within educational settings. In particular, I argue that the mental hygiene movement and the medicalization of education during the late nineteenth and early twentieth centuries, are key historical events that produced an understanding of disabilities as a negative ontologyan undesirable human condition.

The social and historical processes mentioned above are not limited to the mental hygiene movement and the medicalization of education. Due to space limitations, this paper provides only a broad survey of important historical themes and events that present various ways in which the medicalization of education and the mental hygiene movement, in part, framed LD as a negative ontology. Specifically, arguments and evidence are presented on how the advent of mental hygiene movement produced a scientific medical language that increasingly categorized individuals with disabilities as problems and only as problems. I also show that the notion of problematizing individuals 
through medicalization may originate from a tradition of finding ideal populations. In addition, I argue that scientific medical views of personhood and social behaviors during the early twentieth century may be in line with the way people understood their self-identity at that time. As well, medicalization and mental hygienists also prize individualistic explanations for disabilities that characterize individuals with disabilities as self-contained pathologies (Marks, 1999). The paper ends with recommendations for further inquiries into the historical formations and ontological status of LD, in the hopes that such inquiries would provide grounds for promoting a critical consciousness in current educational and social practices, leading to a reframing of LD from a negative ontology to a non-negative ontology.

\section{Mental Hygiene and Medicalization: A Language for Problematizing Others}

Medicalization refers to understanding social problems in medical terms. It also refers to a modern phenomenon where scientific medical language has become a significant influence on everyday life in modern times (Conrad, 2004). Medicalization has provided the common view that $\mathrm{LD}$ is a problem within individuals. The process of locating problems within individuals in medical practices may have contributed a way of speaking and thinking about society and disabilities that categorizes people as problems or non-problems in everyday activities. Danforth and Rhodes (1997) noted that disabilities are social constructions whereby "language, thought, interaction, politics, history and culture" are important in "the making of human meaning in lived contexts" (p. 358). In other words, the current notion of LD is constituted by the ways of thinking and speaking about LD in its historical context. The introduction of medical language and concepts into the lives of parents, educators and society may have provided a way of thinking about LD as a negative ontology and only as a problem (Baker, 2002; Cohen, 1983; Conrad \& Schneider, 1992).

A combination of compulsory education, the entry of the mental hygiene movement into educational settings and the mental hygiene movement's changing of parents' attitudes towards behavioral problems in children in medical terms during the 1920s and 1930s contributed, in part, to understanding children's and adolescents' behavioral differences with a medical and scientific explanation (Cohen, 1983; Petrina, 2006). The mental hygiene movement was founded by Clifford W. Beers, a mental patient, and renowned psychiatrist Adolf Meyer; it was a powerful political initiative partly funded and supported by big corporations such as the Rockefeller Foundation (Richardson, 1987). Cohen and Richardson both noted that an important rationale behind the practices and mission of the mental hygiene movement was that mental problems or deficiencies in people were responsible for the most serious social problems. Mental hygienists believed that the roots of mental problems and illness were located in maladjusted personalities of children; maladjusted personalities could be a result of stress in one's environment.

With the institution of compulsory education in the early 1930s in North America, the mental hygiene movement entered schools because mental hygienists believed that spreading their mission to educational settings would greatly influence society on a larger scale (Cohen, 1983). Cohen noted that a medium that mental hygienists believed was critical in spreading their ideas was parents. According to Cohen, "parent education" (p. 129) was an initiative of the mental hygiene movement; the aims of parent education were targeted towards parents understanding their children and social problems in a medicalized and scientific language. Parental education also provided a situation where medical jargon and beliefs could enter everyday linguistic contexts and lived experiences. Mental hygiene advocates in public schools taught parents how to identify problematic behaviour that reflected mental deficiencies in children (Richardson, 1987). Cohen and Franklin (1987) added that the mental hygiene movement promoted a powerful message to society and that the ways in which the movement promoted its message, in part, formed a way of thinking and speaking about individuals and unacceptable social behavior in terms of medical and scientific concepts. 


\section{Problematizing Others: A Function of Finding Ideal Populations}

Baker (2002) argued that problematizing differences amongst people was the result of a tradition of finding certain types of acceptable persons for an ideal society: a society free of social problems. The mental hygiene movement was closely connected to the ideologies of eugenics; both mental hygiene and eugenics sought to maintain an ideal society (Cohen; 1983; Petrina; 2006; Richardson, 1989). According to Baker (2002), eugenics refers not only to the political movement that attempted to manage a healthier society through techniques such as birth control; eugenics also refers to a complicated and subtle set of discourses about identifying undesired individuals and social traits to achieve an ideal population for society. Such discourses, Baker argued, have become ingrained into current social and institutional practices such as education. Baker suggested that these complex discourses which surround finding undesired individuals are present in everyday actions and conversations. Consistent with Baker's argument, historian Stephen Garton (2000) argued that while the way in which the eugenics movement carried out its mission was widely unacceptable in society during early twentieth century, the ideology of eugenics - seeking ideal populations by removing undesired individuals - remained deeply and subtly ingrained within modern social thought and practices. The mental hygiene movement was closely related to eugenics because it sought to understand problems within individuals (Cohen, 1983). Mental hygienists located social problems within the minds of problematic individuals (Richardson, 1987). Tied even more closely to the eugenics vision of ideal populations was the utopian idea of a problem-free society that numerous mental hygienists embraced and endorsed (Campbell, 2000; Cohen, 1983; Rodwell, 2000). According to Campbell, Garton, and Germov (2000) and Rodwell, unlike eugenicists, who sought to maintain certain types of people by removing others with sterilization and selective breeding, the mental hygiene movement tried to ensure that all humans are functional and abide by social norms. Seen in this light, it may be interpreted that the enterprise of eugenics is to eliminate problematic individuals for an ideal population, whereas the goal of mental hygiene is to ensure an ideal population by identifying problematic individuals in hopes of remediating these individuals to meet the standards of an ideal population.

The reason mental hygienists have been successful in promoting their idea of a problem-free society may be because the movement provided a way of thinking and talking about problematic individuals that was authorized by powerful institutions such as the National Committee of Mental Health and the Rockefeller Foundation (Kovel, 1980). Thus, medical discourses were popularized and also provided much credibility for scientific explanations of socially accepted behaviour and individuals (Franklin, 1987). Richardson (1989) and Petrina (2006) explained that the success of the mental hygiene movement was dependent on earlier institutions such as asylums and dispensaries that promoted the provision of good mental care to children so that children did not become social deviants as adults. School vaccination, for example, was already enforced in some states in the United States as early as the 1820s (Duffy, 1978). Richardson also noted that good mental health of children as an indicator of better life outcomes became widely accepted during early twentieth century. Given the institutional support behind the mental hygiene movement and value-neutrality assumed by scientific and medical explanations in which the mental hygiene movement formed its ideologies coupled with increasing secularization of North American society in the turn of the twentieth century, it is not surprising that medical explanations of behaviour appealed to parents and a large sector of North American society. Secularization refers to the declining influence of religious authority over society and the rise in natural and positivistic sciences to explain human phenomenon (Chaves, 1994; Young, 1979). The decline of religious authority allowed for societies to accept scientific explanations of the world as better ways to understand social behaviour.

Consistent with Richardson's (1987) argument that social institutions and beliefs prior to the establishment of the mental hygiene movement supported its rise, Petrina (2006) argues that a larger scope of inquiry into social practices and mindsets that assisted the ascendancy of the mental hygiene 
movement and the medicalization of education is required for a better understanding of medicalization of education. Petrina offers several arguments. One of which is that the medicalization of education had begun before the initiation of the mental hygiene movement. Intelligence tests, medical inspections, physical education and hygiene instruction were part of educational hygiene, a term coined in 1915 by educator Louis Rapeer (as cited in Petrina, 2006). Educational hygiene promoted practices such as physical education and school sanitation, in part, as social control tools that were believed to ensure moral standards within educational settings. According to Petrina, practices of educational hygiene were also believed to prevent social problems in future. Petrina and Cohen (1983) also documented evidence of certain social practices in schools that were intended to maintain certain desirable traits in people. Physical fitness, an example that Petrina and Cohen highlighted, was believed to improve student's moral character. Coinciding with the mental hygiene movement, the ascendancy of psychotherapy and psychiatry was also closely related to the medical model of understanding deviant social behaviour and also shaped the idea that individuals and social behavior can be understood in terms of a value-free scientific paradigm (Kovel, 1980; Cushman, 1990; 1995). As a result of medicalization, understanding $\mathrm{LD}$ as a negative ontology became an acceptable way to view learning problems.

\section{Defining Personbood: Defining Problems}

Medical and scientific explanations of personhood and social behaviors at the time of the mental hygiene movement's ascendancy may have appealed to the way in which people understood their selfidentity (Cushman, 1995). Cushman (1990) noted that self or the concept of individual identity in North America is characterized by a deep-seated emptiness within the individual. The emptiness within a person, Cushman argues, arose from a traditional understanding of problematizing others - defining one's self in terms of personal qualities that one does not desire. Such a definition of self suggests that an ideal conception of one's identity begins first with understanding one's self in terms of undesirable qualities of others; only after identifying negative qualities can one begin to find a basis for an ideal personhood. Mental hygiene, according to Cushman, was a technology of the self and was instrumental in laying the foundational framework for understanding one's personhood in terms of a predominantly scientific and medical language. In addition, it seemed that mental hygiene, along with the mindset of identifying one's self by first identifying undesirable traits in others, provided a crucial platform for problematizing other people and locating the causes of deviant behaviours as biological and innate deficits within individuals.

Identity was increasingly understood in medical terms such as normal/abnormal, disabled/able and in terms of mental health during the early twentieth century and it continues to be. (Stiker, 2000; Conrad, 2004) While Petrina (2006) suggests that medicalization of society began in social practices and ideologies about moral behaviour before the mental hygiene movement, he also proposed that those practices such as vaccinations may have laid important foundations for the mental hygiene movement to be socially accepted. As a result, the mental hygiene movement was a successful political movement that changed the way in which members of a society understand social problems. Furthermore, the movement promoted the concept of problematizing others at a political and social scale that had never before been witnessed in history (Richardson, 1989).

\section{Moral and Individualistic Explanations of Disabilities}

Similarly, Joel Kovel (1980) traced the history of the mental health industry in North America and argued that the mental hygiene movement provided a strong impetus which explained how the individual came to be scrutinized as individual problem objects. Problems that were once moralized came to be framed in a medical and scientific manner with the help of the mental hygiene movement. Conrad and Schneider (1992) noted that before the advent of medicalization, socially deviant behavior was understood more as a moral issue concerning the community than a medical concern. Deviant 
behavior was an issue that was not solely explained in terms of individual deficits. This does not mean that the community was responsible for socially deviant behavior. Rather, it meant that instead of being a consequence of problems within one's biological or innate constitution, mental ailments were a result of not conforming to shared moral norms within the community. Unlike the current definition and mainstream notions of LD that defines LD as a stable neurological deficit, disability was seen as a shared concern within one's community whereby the status of the disability could be negotiated and discussed by individuals of the community. However, it should be cautioned that such discussions may not have taken the form of a democratic dialogue. Further historical inquiry may be required to address the ways in which disabilities were understood before medicalization in modern times.

Similar to Conrad and Schneider's (1992) notion of social deviant behaviour, Neaman (1975) explained that in medieval times, theological explanations were prime explanations of mental illnesses. Madness, as suggested by Neaman, was a general term used to categorize many types of unacceptable social behaviours; the cause of these socially deviant behaviours was believed to be God's punishment for bad moral behaviour. Nonetheless, mad individuals were not isolated from, but were part of everyday activity during medieval times. Likewise, Szasz (1974) contends that medicine and the medical establishment gradually replaced moral and religious authorities on social behavior (i.e., the Church) as the dominant institution of social control after the Middle Ages. Following the increasing influence of medicalization, the problems classified under madness were defined in a medical language with an increasing tendency to attribute social problems to individual mental illnesses. This redefinition of deviant behavior in medical and scientific terms did not adopt a view of mental illness as an individualized morally neutral problem until much later, towards the early twentieth century (Conrad \& Schneider, 1992). Conrad and Schneider also argued that despite the growing dominance of medicine in early twentieth century, medical practitioners still advocated a moral treatment for mental illnesses. Moral beliefs are shared values, thus mental problems were not understood as individual pathologies that only resided within individuals. Szasz (1974) suggests that within industrializing capitalist societies in the nineteenth century, individualistic views of mental problems became increasingly prominent. Mental illnesses were considered to be socially unacceptable, thus shameful. Keeping mental illnesses as a private and individual matter helped patients cope with the shame of mental illness. As industrializing societies prized the able-bodied worker, making public the knowledge of one's mental illness also jeopardized one's employment and livelihood (Engels, 1958; Marks, 1999; French, 2001; Oliver, 2000). Szasz (1974) argues that keeping mental illnesses private provided an impetus for modern medical institutions to set up and maintain medical practices in a practitioner-to-patient arrangement to protect the privacy of both patients and medical practitioners, making the medical experience a private and individualized one. Medical practices that were set up in such a manner, in turn, strengthened the understanding that mental illnesses were a matter that involved primarily the individual.

Thus, it is crucial to acknowledge that the term and the concept of LD was introduced against a historical and social backdrop in North America that increasingly fixed its understanding of human differences in terms of problems, defining deviant behavior with medical terminologies, and viewing individual patients as self-contained pathologies (Marks, 1999). Such scientific ways of understanding behavioral differences in humans was a type of discourse that problematized and pathologized deviant individuals. LD was a term that was initially defined for educational purposes (Sleeter, 1987). However, the way in which it was first defined and framed was consistent with the medical way of framing one's learning challenges in one's neurobiological make-up. Medicalization endorsed the understanding of LD as a "conundrum" (Campbell, 2000, p. 307) that was framed in a scientific language and that was ascribed as value neutral during a period of rising secularization in North America.

Evidence to demonstrate that LD was not necessarily used as an educational category that benefited children and parents, but as a label for deviant social behavior in classrooms comes from studies reporting incidents of educational professionals using LD as a label for disruptive students who may not have had specific learning handicaps or genuine neurological problems (Carrier, 1986). Although the medical emphasis on learning disabilities became gradually more diffused (Franklin, 
1987), particularly in the light of educational assistance provided for learning disabled students, it left in the public a legacy of understanding learning disabilities as a problem. After the inception of LD as a social category and because of the scientific inquiry into LD as a psychological/biological/medical phenomenon, LD became increasingly framed as a pathology and a negative ontology.

\section{Conclusion}

Medicalization of education and the mental hygiene movement alone may not have been sufficient to produce and sustain a common understanding of LD as a negative ontology. A combination of social practices and ideologies within education, medicalization and social processes outside of education and medicalization during and following the conception of LD as an educational category may have contributed to common knowledge of LD as a negative ontology. For the purpose of this paper, I have chosen to focus on the influence of medicalization and the mental hygiene movement on education because much of scholarly discussions on LD are steeped in scientific medical language (Christensen, 1999; Franklin, 1987). In particular, I have highlighted that the understanding of LD as a negative ontology may have had its origins in a tradition of viewing socially different behaviors and individuals as a problem and only as a problem. Viewing undesired behaviors as problems work to justify the pursuit of ideal populations for a so-called good, problem-free society. An ideal population and ideal norms cannot lead to a truly democratic society. Rather, a good democratic society should not consist only of ideal persons; an ideal society should find all types of people. My argument does not dispute norms but instead attempts to frame norms as an ongoing discussion and a public debate as opposed to a static or exclusive category.

The historical arguments and discussions put forth within this paper are secondary historical sources. Thus, this paper, at best, serves as a surface and general dig at numerous historical and formative issues contributing to the current view of LD. Further historical investigations into issues discussed in this paper are required for a more informed understanding of the social, historical and ontological processes that produced current understanding of LD. In particular, more historical detail concerning the establishment of the mental hygiene movement may be necessary for a historically situated understanding of the emergence of LD. In addition, further inquiry into specific historical examples of the links between eugenics and the mental hygiene movement would further deepen our understanding of the complexities involved in the formation of past and current LD models.

Several scholars have highlighted how historical analyses of the ontology of LD can help reframe $\mathrm{LD}$ as a non-negative ontology. Understanding $\mathrm{LD}$ as a non-negative ontology allows educators to focus on the strengths of students with LD. For example, Graham and Grieshaber (2006) highlighted that educators are often fixated on expecting all students to fit a certain academic achievement standard. For Graham and Grieshaber, students who fall outside such achievement standards are often problematized. They advocate finding the strengths of students and helping students use their strengths to reach their potential. In other words, they also note that individuals with LD should not be seen solely as problems. Instead, for Graham and Grieshaber, individuals with LD are empowered when they focus on their strengths. However, before individuals with LD can be viewed more positively, Graham and Grieshaber urge an appreciation of the practices that frame LD and individuals with LD as problems. Thus, an understanding of historical formations of LD can help educators better understand the negative practices that describe students with LD as problems only.

Lastly, this paper also serves as a call for a more unified field of LD and to understand LD more positively. Thus, a consciousness that is critical of the historical formations of our current practices is required to effect changes to current views of LD. I hope that with greater awareness of the historical formations of $\mathrm{LD}$ as a negative ontology, practitioners, educators, parents and society would understand that an overemphasis on identifying learning and social problems in individuals with LD may itself be disabling and that perhaps shifting focus to understand the unique learning abilities of 
individuals who are seen as learning disabled may empower the lives of these individuals and enhance their learning.

\section{Acknowledgments}

This paper was presented at Education without Borders, Fall 2008. I am grateful to Dr. Paul Neufeld for his encouragement and the many invested discussions we had. I am also thankful for the reviewers who did a thorough review of my manuscripts and provided me with new insights.

\section{References}

Baker, B. (2002). The hunt for disability: The new eugenics and the normalization of school children. Teachers College Record ,104, 663-703.

Brantlinger, E. (2004). Confounding the needs and confronting the norms: An extension of Reid and Valle's essay. Journal of Learning Disabilities, 37, 490-499.

Campbell, F. A. (2000). Eugenics in a different key? New technologies and the 'conundrum' of 'disability'. In M. Crotty, J. Germov, \& G. Rodwell (Eds.) "A race for a place”: Eugenics, Darwinism, and social thought and practice in Australia. (pp. 307-317). Newcastle, AU: The University of Newcastle Press.

Campbell, F. K. (2005). Legislating disability: Negative ontologies and the government of legal identities. In S. Tremain (Ed.), Foucault and the government of disability. (pp.108-132). Ann Arbor: The University of Michigan Press.

Carrier, J. G. (1983). Masking the social in educational knowledge: The case of learning disability theory. American Journal of Sociology, 88, 948-974.

Carrier, J. G. (1986). Social class and the construction of inequality in American education. New York: Greenwood Press.

Chaves, M. (1994). Secularization as declining religious authority. Social Forces, 72, 749-774.

Christensen, C. A. (1999). Learning disabilities: Issues of representation, power, and the medicalization of school failure. In R.J. Sternberg, \& L. Spear-Swerling (Eds.) Perspectives on learning disabilities: Biological, cognitive and contextual. (pp. 227-249). Colorado: Westview Press.

Cohen, S. (1983). The mental hygiene movement, the development of personality and the school: The medicalization of American education. History of Education Quarterly, 23, 123-149.

Conrad, P. (2004). The medicalization of society: on the transformation of human condition to treatable disorders. New York: John Hopkins University Press.

Conrad, P., \& Schneider, J. W. (1992). Deviance and medicalization: From badness to sickness. Philadelphia: Temple University Press.

Cushman, P. (1990). Why the self is empty: Toward a historically situated psychology. American Psychologist, 45, 599-611.

Cushman, P. (1995). Constructing the self, constructing America: A cultural history of psychotherapy. United States: Da Capo Press.

Danforth, S., \& Rhodes, W. (1997). Deconstructing disability: A philosophy for inclusion. Remedial and Special Education, 18, 357-66.

Danforth, S., \& Gabel, S. (2006). Introduction. In S. Danforth \& S. Gabel (Eds.), Vital questions facing disability studies in education. (pp.1 -16).New York: Peter Lang Publishing. 
Danforth, S. (2006). Learning from our historical evasions: Disability studies and schooling in a liberal democracy. In S. Danforth \& S. Gabel (Eds.), Vital questions facing disability studies in education. (pp.77-90). New York: Peter Lang Publishing.

Dudley-Marling, C. (2004). The social construction of learning disabilities. Journal of Learning Disabilities, 37, 482-489.

Duffy, J. (1978). School vaccinations: The precursor to school medical inspection. Journal of the History of Medicine and Allied Sciences, 33, 344-355.

Engels, F. (1958). The condition of the working class in England. Stanford, California: Stanford University Press.

Franklin, B. M. (1987). The first crusade for learning disabilities: The movement for the education of backward children. In T. S. Popkewitz, (Ed.) The formation of the school subjects. (pp.190-209). New York: The Falmer Press.

Garton, S. (2000). Writing eugenics: A history of classifying practices. In M. Crotty, J. Germov, \& G. Rodwell (Eds.) "A race for a place": Eugenics, Darwinism, and social thought and practice in Australia. (pp.9- 18). Newcastle, AU: The University of Newcastle Press.

Graham, L., \& Grieshaber, S. (2006). Reading dis/ability: Interrogating paradigms in a prism of power. Disability \& Society, 23, 557-570.

Hallahan, D. P., \& Devery R. M. (2003). A brief history of the field of learning disabilities. In H. L. Swanson, K. R. Harris, \& S. Graham (Eds.) Handbook of learning disabilities. (pp.16-29). New York: The Guildford Press.

Hynd, G. W., Clinton, A. B., \& Hiemenz, J. R.(1999). The neuropsychological basis of learning disabilities. In R. J. Sternberg, \& L. Spear-Swerling (Eds.) Perspectives on learning disabilities: Biological, cognitive and contextual. (pp.60-82). Colorado: Westview Press.

Kavale, K. A. \& Forness, S. R. (2003). Learning disability as a discipline. In H. L. Swanson, K. R. Harris \& S. Graham (Eds.) (pp.76-93). Handbook of learning disabilities. New York: The Guildford Press.

King, J. E. (1991). Dysconscious racism: Ideology, identity, and the miseducation of teachers. Journal of Negro Education, 60, 133-146.

Kovel, J. (1980). The American mental health industry. In D. Inglesby (Ed.), Critical psychiatry: The politics of mental health. (p. 72-101). New York: Random House.

Marks, D. (1999). Disability: Controversial debates and psychosocial perspectives. London: Routledge.

Marx, K. (1967). Capital: A critique of political economy. New York: International Publishers.

Neaman, J. S. (1975). Suggestions of the devil: The origins of madness. New York: Anchor Books.

Neufeld, P., \& Hoskyn, M. (2004). Learning disabilities and the new reductionism: A response to Reid and Valle. Journal of Learning Disabilities, 38, 183-187.

Neufeld, P., \& Takacs, S. (2006). Learning disabilities, schools and neurological dysfunction. Journal of Thought, 21(4), 103-115.

Oliver, M. J. (2001). Capitalism, disability and ideology: A materialist critique of the normalization principle. Available at (www.jiscmail.ac.uk/lists/disability-research.html).

Petrina, S. (2006). The medicalization of education: A historiographic synthesis. History of Education Quarterly, 46, 503-531.

Reid, K., \& Valle, J. W. (2004). The discursive practice of learning disability: Implications for instruction and parent-school relations. Journal of Learning Disabilities, 37, 466-481.

Richardson, T. A. (1989). The century of the child: The Mental Hygiene Movement and social policy in the United States and Canada. New York: State University of New York Press.

Rodwell, G. (2000). The unkindest cut of all: eugenics, masturbation and circumcision. In M. Crotty, J. Germov, \& G. Rodwell (Eds.), "A Race for a place”: Eugenics, Darwinism and social thought and practice in Australia (pp. 235-247). Newcastle, Australia: The University of Newcastle Press.

Skrtic, T. M. (1999). Learning disabilities as organizational pathologies. . In R. J. Sternberg, \& L. SpearSwerling (Eds.), Perspectives on learning disabilities: Biological, cognitive and contextual. (pp. 193-226). Colorado: Westview Press. 
Sleeter, C. (1987). Why is there learning disabilities? A critical analysis of the birth of the field in its social context. In T. S. Popkewitz, (Ed.) The formation of the school subjects. (pp.210-237). New York: The Falmer Press.

Szasz, T. S. (1974). The myth of mental illness: Foundations of a theory of personal conduct. Toronto: Harper \& Row.

Stiker, H. (2000). A bistory of disability. (W. Sayers, Trans.). Ann Arbor: The University of Michigan Press. (Originally work published in 1997).

Swanson, H. L., Harris, K. R., \& Graham. (2003). Overview of foundations, causes, instruction and methodology in the field of learning disabilities. In H. L. Swanson, K. R. Harris \& S. Graham (Eds.) Handbook of learning disabilities. (pp.3-16). New York: The Guildford Press.

Young, R. M. (1979). The naturalization of value systems in human sciences. In M. Keynes (Ed.), Problems in the Biological and Human Sciences. (p.63-110). London: Open University Press.

\section{About the Author}

Sai Tzy Horng is an M.A Candidate in the Educational Psychology program at Simon Fraser University. His research interests are in the historical formation of boredom and subjective experience in a modern and consumer society. 